\title{
Arrival and Departure Flights Sequencing Optimization Based on Flight Classification Model
}

\author{
Xiong $\mathrm{Li}^{1, *}$, Xiaoqing Chen ${ }^{2}$, Dongbin $\mathrm{Li}^{3}$ and Dongxuan $\mathrm{Wei}^{4}$ \\ ${ }^{1}$ Planning and Design Institute, China Airport Construction Group Corporation, Beijing, China \\ ${ }^{2}$ Aviation Industry Development Research Center of China, Beijing, China \\ ${ }^{3}$ Department of Air Traffic Management, Civil Aviation of Management Institute of China, Beijing, China \\ ${ }^{4}$ Highway School, Chang'an University, Xi’an, Shanxi, China \\ ${ }^{*}$ Corresponding author
}

\begin{abstract}
Delicacy flight classification and calculation of delay cost is very important for improving airport operation efficiency and reducing airline operation cost, when it is applied to manage the sequence of take-off and landing flights. The four different factors were considered, and the transitive closure algorithm (TCA) was used to classify the flight. The TCA method was implemented in sequencing problems of arrival and departure flights in large airport, and compared with the traditional classification method. Results indicate that the TCA classification model is conducive to reduce the expenses of flight delays, optimize the sequences of arrival and departure flights, and improve the efficiency of airport operation.
\end{abstract}

Keywords-air traffic management; flight classification; transitive closure algorithm; sequencing; airport operation

\section{INTRODUCTION}

The continuous growth of social economy drives China air transport on the fast-growing track, during which China civil aviation has become the second largest air transport system in the world. The delicacy flight classification and calculation of delay cost is very important for improving airport operation efficiency and reducing airline operation cost, when it is applied to manage the sequence of take-off and landing flights. Odoni gave a systematic description of ATFM problems first in 1987. Since then, many researchers have proposed their own air traffic control models with the aim of reducing the total delay costs. However, among these models, there are still some drawbacks in calculating the cost of flight delays (CFD), i.e., (1)for each flight the delay cost per minute is identical(e.g. \$50 for ground delay, \$75 for airborne delay)[1-4]; (2)all flights are classified into only three cost classes according to the maximum take-off weight (MTOW)[5,6]. As the foundation of the objective functions in aforementioned models, it is necessary to determine CFDs scientifically.

Based on the above analysis, a flight classification method, which considers a variety of factors, is proposed[7]. All kinds of flights will be categorized by the transitive closure algorithm (TCA) based on 4 different factors, i.e., MTOW, maximum payload, average fuel consumption per hour (or wring span), and grade of importance. It could be used to solve dynamic clustering problems of arrival/departure (A/D) flights in large airport during congestion periods, and calculate CFDs according to the different classes of flights. To assess the performance of this method, we make a comparison between this method and the traditional classification method, when dealing with sequencing problems of $\mathrm{A} / \mathrm{D}$ flights in large airport.

\section{Flights ClassificAtion ModeI}

The characteristics of arrival flights include 4 factors: MTOW, maximum payload (MP), average fuel consumption per hour (AFCH), and grade of importance (GI). Similarly, the characteristics of departure flights include MTOW, AFCH, wring span (WS), and GI. So, the parameter $m$ in this flights classification model is 4 . Note that for the factor GI, the values $100,50,10$, and 5 represent, respectively, special plane flight, very important person flight, international flight and domestic flight.

In each congestion period, if there are $n(n \geq 5)$ flights waiting for landing or taking-off per hour, we would divide them according to their characteristics by TCA. Among the existing fuzzy clustering algorithms, the most frequently used fuzzy clustering technique is TCA, which is based on fuzzy similar relations and fuzzy equivalent relations. It can partition the sample set into several clusters under different threshold values.

If $n$ arrival or departure flights are classified into $S$ classes by the model, then each class is defined the $s$ th class according to decreasing mean values of GIs (if equal, according to decreasing mean values of MTOWs), $s=1,2, \cdots, s$, denoted with Roman numerals I, II, III... For example, assume that there are 6 arrival flights (F01, F02, ... F06), and they have been classified into 3 classes. The mean values of GIs for each class are 30, 10 and 5 respectively, i.e., the first class(F01, F03) 30, the second class(F02, F05) 10, the third class(F04, F06) 5. So the classification result is I Class $\{\mathrm{F} 01, \mathrm{~F} 03\}$, II Class $\{\mathrm{F} 02$, F05\} and III Class $\{$ F04, F06 $\}$. For arrival and departure flights the costs of delays per minute (CDPM) to the $s$ th class are $[4 \times(S-s)+1] c_{a}$ and $[4 \times(S-s)+1] c_{g}$, respectively. Thereinto, $c_{a}$ and $c_{g}$ represent the airborne and ground delay cost unit respectively, $c_{a}>c_{g}$.

The time complexity of this model is $O\left(n^{3} \log _{2}^{n}\right)$, and its space complexity is $O\left(n^{2}\right)$ [8]. In most circumstances, the 
number of arrival or departure flights per hour is no more than 60 (i.e., $n \leq 60$ ), so we can get the classification result easily in one second by using a PC with $2.0 \mathrm{GHz} \mathrm{CPU}$ and $512 \mathrm{MB}$ RAM.

\section{SiMULATION INSTANCES}

\section{A. Flight Classification Data}

Two instances are taken to demonstrate the performance of the presented method. One instance is that 10 arrival flights wait for landing during 10:00-11:00 in a single-runway airport; the other is that 6 departure flights wait for taking off during 14:00-15:00 in the same airport. The data of these flights are shown in Table 1 and 2.

TABLE I. ARRIVAL FLIGHTS DURING 10:00-11:00

\begin{tabular}{|c|c|c|c|c|}
\hline Flight NO. / Type & MTOW (kg) & MP (kg) & AFCH (kg) & GI \\
\hline F001 / B737-800 & 70553 & 17000 & 2650 & 5 \\
\hline F002 / A300-600 & 170500 & 38000 & 5500 & 10 \\
\hline F003 / B777-200 & 229517 & 51396 & 7200 & 10 \\
\hline F004 / B737-300 & 61234 & 15331 & 2500 & 5 \\
\hline F005 / B767-300 & 163293 & 36466 & 5000 & 10 \\
\hline F006 / ATR-72 & 22500 & 7450 & 710 & 5 \\
\hline F007 / B747-400 & 385557 & 75297 & 11000 & 100 \\
\hline F008 / A318 & 59000 & 11100 & 1900 & 5 \\
\hline F009 / CRJ-200 & 21500 & 5400 & 700 & 5 \\
\hline F010 / A340-300 & 275000 & 45000 & 6800 & 10 \\
\hline
\end{tabular}

TABLE II. DEPARTURE FLIGHTS DURING 14:00-15:00

\begin{tabular}{|c|c|c|c|c|}
\hline Flight NO. / Type & MTOW (kg) & MP (kg) & AFCH (kg) & GI \\
\hline F011 / B767-300 & 163293 & 36466 & 47.6 & 10 \\
\hline F012 / B777-200 & 229517 & 51396 & 60.9 & 10 \\
\hline F013 / B737-800 & 70553 & 17000 & 34.3 & 5 \\
\hline F014 / A340-300 & 275000 & 45000 & 60.3 & 10 \\
\hline F015 / Y-12 & 5300 & 1700 & 17.2 & 5 \\
\hline F016 / MD82 & 67800 & 19700 & 32.9 & 5 \\
\hline
\end{tabular}

\section{B. Flight Classification Results}

For 10 arrival flights in Table 1, by using TCA, we obtain the transitive closure after 4 times square:

$\left[\begin{array}{llllllllll}1.00 & 0.48 & 0.48 & 0.91 & 0.48 & 0.52 & 0.48 & 0.82 & 0.52 & 0.48 \\ 0.48 & 1.00 & 0.76 & 0.48 & 0.95 & 0.48 & 0.51 & 0.48 & 0.48 & 0.76 \\ 0.48 & 0.76 & 1.00 & 0.48 & 0.76 & 0.48 & 0.51 & 0.48 & 0.48 & 0.89 \\ 0.91 & 0.48 & 0.48 & 1.00 & 0.48 & 0.52 & 0.48 & 0.82 & 0.52 & 0.48 \\ 0.48 & 0.95 & 0.76 & 0.48 & 1.00 & 0.48 & 0.51 & 0.48 & 0.48 & 0.76 \\ 0.52 & 0.48 & 0.48 & 0.52 & 0.48 & 1.00 & 0.48 & 0.52 & 0.89 & 0.48 \\ 0.48 & 0.51 & 0.51 & 0.48 & 0.51 & 0.48 & 1.00 & 0.48 & 0.48 & 0.51 \\ 0.82 & 0.48 & 0.48 & 0.82 & 0.48 & 0.52 & 0.48 & 1.00 & 0.52 & 0.48 \\ 0.52 & 0.48 & 0.48 & 0.52 & 0.48 & 0.89 & 0.48 & 0.52 & 1.00 & 0.48 \\ 0.48 & 0.76 & 0.89 & 0.48 & 0.76 & 0.48 & 0.51 & 0.48 & 0.48 & 1.00\end{array}\right]$

Choose $\lambda=0.8$ and cut the matrix above. Then, we can get 5 classes: I Class $\{\mathrm{F} 007\}$, II Class $\{\mathrm{F} 003, \mathrm{~F} 010\}$, III Class $\{$ F002, F005\}, IV Class $\{$ F001, F004, F008\}, V Class $\left\{\right.$ F006, F009\}; their CDPMs are $17 c_{a}, 13 c_{a}, 9 c_{a}, 5 c_{a}$ and $1_{c_{a}}$, respectively.

Similarly, after 3 times square, we can get the transitive closure of Table 2:

$$
\left[\begin{array}{llllll}
1.00 & 0.75 & 0.56 & 0.75 & 0.35 & 0.56 \\
0.75 & 1.00 & 0.56 & 0.91 & 0.35 & 0.56 \\
0.56 & 0.56 & 1.00 & 0.56 & 0.35 & 0.93 \\
0.75 & 0.91 & 0.56 & 1.00 & 0.35 & 0.56 \\
0.35 & 0.35 & 0.35 & 0.35 & 1.00 & 0.35 \\
0.56 & 0.56 & 0.93 & 0.56 & 0.35 & 1.00
\end{array}\right]
$$

The 6 departure flights are divided into 4 classes with the same threshold value $\lambda$ :I Class $\{$ F012, F014\}, II Class $\{$ F011\}, III Class $\{$ F013, F016\}, IV Class $\{$ F015 $\}$; their CDPMs are: $13_{c_{g}}, 9_{c_{g}}, 5_{c_{g}}$ and $1_{c_{g}}$, respectively.

\section{Application in Flights Sequencing Problem}

In order to test the new classification method is helpful to optimize the sequence of $\mathrm{A} / \mathrm{D}$ flights, we introduce the sequencing problem in terminal area, and make a comparison between using TCA and the traditional classification method (TCM). In flights sequencing problem, the objective is to find a flights sequence whose total cost of delays is lowest.

In TCM aircrafts are classified into 3 classes according to MTOW[9]: Small Aircraft (S) with less than $5670 \mathrm{~kg}$; Medium/Large (M/L) Aircraft, between 5670 and $136080 \mathrm{~kg}$; Heavy $(\mathrm{H})$ Aircraft with over $136080 \mathrm{~kg}$. The classification results and the sequence results (SR) of A/D flights based on both methods are reported in Table $3 \sim 6$, respectively. For the purpose of making a fair comparison, we calculate the CFDs based on TCM by using the same CDMPs as we do in TCA. Notice that the time for landing or taking off is 2 minutes, and the flight cannot land (or take off) before its ETA (or ETD).

TABLE III. RESULTS FOR ARRIVAL FLIGHTS SEQUENCE BY USING TCM

\begin{tabular}{|c|c|c|c|c|c|}
\hline \multirow{2}{*}{$\begin{array}{c}\text { Flight } \\
\text { NO. }\end{array}$} & \multirow{2}{*}{ ETA } & \multicolumn{5}{|c|}{ TCM } \\
\cline { 3 - 6 } & & Class & SR & STA & CFD \\
\hline F001 & $10: 00$ & $\mathrm{M} / \mathrm{L}$ & 6 & $10: 10$ & 50 \\
\hline F002 & $10: 00$ & $\mathrm{H}$ & 1 & $10: 00$ & 0 \\
\hline F003 & $10: 00$ & $\mathrm{H}$ & 2 & $10: 02$ & 26 \\
\hline F004 & $10: 02$ & $\mathrm{M} / \mathrm{L}$ & 7 & $10: 12$ & 50 \\
\hline F005 & $10: 02$ & $\mathrm{H}$ & 3 & $10: 04$ & 18 \\
\hline F006 & $10: 04$ & $\mathrm{M} / \mathrm{L}$ & 8 & $10: 14$ & 10 \\
\hline F007 & $10: 04$ & $\mathrm{H}$ & 4 & $10: 06$ & 34 \\
\hline F008 & $10: 06$ & $\mathrm{M} / \mathrm{L}$ & 9 & $10: 16$ & 50 \\
\hline F009 & $10: 08$ & $\mathrm{M} / \mathrm{L}$ & 10 & $10: 18$ & 10 \\
\hline F010 & $10: 08$ & $\mathrm{H}$ & 5 & $10: 08$ & 0 \\
\hline Total Cost of Airborne Delays/ $C_{a}: 248$ \\
\hline
\end{tabular}


TABLE IV. RESULTS FOR ARRIVAL FLIGHTS SEQUENCE BY USING TCA

\begin{tabular}{|c|c|c|c|c|c|}
\hline \multirow{2}{*}{$\begin{array}{c}\text { Flight } \\
\text { NO. }\end{array}$} & \multirow{2}{*}{ ETA } & \multicolumn{4}{|c|}{ TCA } \\
\cline { 3 - 6 } & & Class & SR & STA & CFD \\
\hline F001 & $10: 00$ & IV & 6 & $10: 10$ & 50 \\
\hline F002 & $10: 00$ & III & 2 & $10: 02$ & 18 \\
\hline F003 & $10: 00$ & II & 1 & $10: 00$ & 0 \\
\hline F004 & $10: 02$ & IV & 7 & $10: 12$ & 50 \\
\hline F005 & $10: 02$ & III & 4 & $10: 06$ & 36 \\
\hline F006 & $10: 04$ & V & 9 & $10: 16$ & 12 \\
\hline F007 & $10: 04$ & I & 3 & $10: 04$ & 0 \\
\hline F008 & $10: 06$ & IV & 8 & $10: 14$ & 40 \\
\hline F009 & $10: 08$ & V & 10 & $10: 18$ & 10 \\
\hline F010 & $10: 08$ & II & 5 & $10: 08$ & 0 \\
\hline Total Cost of Airborne Delays/ $C_{a}: 216$ & \\
\hline
\end{tabular}

In the above table, ETA represents the estimated time of arrival, STA represents the scheduled time of arrival; in the following table, ETD represents the estimated time of departure, STD represents the scheduled time of departure.

\section{TABLE V. RESULTS FOR DEPARTURE FLIGHTS SEQUENCE BY} USING TCM

\begin{tabular}{|c|c|c|c|c|c|}
\hline $\begin{array}{c}\text { Flight } \\
\text { NO. }\end{array}$ & \multirow{2}{*}{ ETD } & \multicolumn{4}{|c|}{ TCM } \\
\cline { 3 - 6 } & & Class & SR & STA & CFD \\
\hline F011 & $14: 00$ & $\mathrm{H}$ & 1 & $14: 00$ & 0 \\
\hline F012 & $14: 00$ & $\mathrm{H}$ & 2 & $14: 02$ & 26 \\
\hline F013 & $14: 02$ & $\mathrm{M} / \mathrm{L}$ & 4 & $14: 06$ & 20 \\
\hline F014 & $14: 02$ & $\mathrm{H}$ & 3 & $14: 04$ & 26 \\
\hline F015 & $14: 04$ & $\mathrm{~S}$ & 6 & $14: 10$ & 6 \\
\hline F016 & $14: 04$ & $\mathrm{M} / \mathrm{L}$ & 5 & $14: 08$ & 20 \\
\hline \multicolumn{7}{l|}{ Total Cost of Airborne Delays/ $\boldsymbol{C}_{g}: 98$} \\
\hline
\end{tabular}

TABLE VI. RESULTS FOR DEPARTURE FLIGHTS SEQUENCE BY USING TCA

\begin{tabular}{|c|c|c|c|c|c|}
\hline Flight & \multirow{2}{*}{ ETD } & \multicolumn{4}{|c|}{ TCA } \\
\cline { 3 - 6 } & & Class & SR & STA & CFD \\
\hline F011 & $14: 00$ & II & 3 & $14: 04$ & 36 \\
\hline F012 & $14: 00$ & I & 1 & $14: 00$ & 0 \\
\hline F013 & $14: 02$ & III & 4 & $14: 06$ & 20 \\
\hline F014 & $14: 02$ & I & 2 & $14: 02$ & 0 \\
\hline F015 & $14: 04$ & IV & 6 & $14: 10$ & 6 \\
\hline F016 & $14: 04$ & III & 5 & $14: 08$ & 20 \\
\hline \multicolumn{7}{l}{ Total Cost of Airborne Delays/ $C_{g}: 82$} \\
\hline
\end{tabular}

From Table $3 \sim 6$, it is apparent that the total cost of delays based on TCA is lower than that based on TCM. The total cost of delays during 10:00-11:00 and 14:00-15:00 decrease 12.9\% and $16.3 \%$ respectively by using TCA. It is mainly because the waiting time of flights with higher CDPMs is reduced by using the new classification method, e.g., F007/B747-400 suffers a delay of 2 minutes in TCM, but no delays in TCA.

\section{CONCLUSIONS}

A new A/D flights classification model based on TCA is analyzed in this paper. By using TCA all flights can be classified more exactly than using traditional classification method in consideration of 4 different factors. Besides, we give the CDPM for each flights class, which is the foundation when establishing various ATFM models. The new method is conducive to optimize the sequences of A/D flights and reduce the expenses of delays. The cost of flight delays for arrival and departure flights has reduced about $15 \%$ by using TCA.

\section{ACKNOWLEDGMENT}

This work was supported by China civil aviation security ability building funds (2016)--Research on application of simulation technology in civil airport planning and design.

\section{REFERENCES}

[1] S.S. Pulugurtha, S.S Nambisan, "Using genetic algorithms to evaluate aircraft ground holding policy under static conditions," Journal of Transportation Engineering, vol. 127, 2001, pp. 433-441.

[2] X. Zhang, H Ye, "Air traffic flow management by use of flight routes and aerodrome areas as nodes," Journal of Southwest Jiaotong University, vol. 37, 2002, pp. 61-64.

[3] L. Brunetta, G. Guastalla, L. Navazio, "Solving the multi-airport ground holding problem,” Applied Mathematical Programming and Modeling III, Uxbridge, UK, 1995, pp. 271-287.

[4] G. Andratta, L. Brunetta, "Multiairport ground holding problem: a computational evaluation of exact algorithms," Operations Research, vol. 46, 1998, pp. 57-64.

[5] M. Terrab, S. Paulose, "Dynamic strategic and tactical air traffic flow control," IEEE International Conference on Systems, Man and Cybernetics, Chicago, USA, 1992, pp. 243-248.

[6] O. Richetta, A. R. Odoni, "Solving optimally the static ground-holding policy problem in air traffic control,” Transportation Science, vol. 27, 1993, pp. 228-238.

[7] X. Li, X. Q. Chen, F. Li, "Flight classification method based on unit time delay cost," International Conference on Modeling, Simulation and Analysis, Wuhan, China, in press.

[8] L. Shi, P. He, "A fast fuzzy clustering algorithm for large-scale datasets," Advanced Data Mining and Applications. Wuhan, China, 2005, pp. 203-208.

[9] O. Richetta, A. R Odoni, "Solving optimally the static ground-holding policy problem in air traffic control," Transportation Science, vol. 27, 1993, pp. 228-238. 